\title{
Eagle Syndrome- Transcervical vs. Transoral approach
}

\section{Introduction}

Eagle syndrome is a rare, commonly under diagnosed, condition caused by an elongated styloid process or calcified stylohyoid ligament causing pressure effects on various structures, such as the glossopharyngeal nerve. Typical presenting symptoms include odynophagia, dysphagia and foreign body sensation; with pain elicited by palpation of the tonsillar fossae. We present two cases of Eagle syndrome treated by two standard surgical methods, and discuss the advantages and disadvantages of each.

\begin{abstract}
Case 1- Transcervical approach
\section{Case presentation}

57 year old gentleman referred by his GP to the otolaryngology department with 6 week history of persistent sore throat and dry throat but no other red flag symptoms. An ENT examination revealed only slight oedema to right arytenoid region. CT scan was performed which revealed abnormal calcification of the right stylohyoid ligament, in excess of $4 \mathrm{~cm}$ length.
\end{abstract}

\section{Procedure}

The patient underwent external (transcervical) excision of the right styloid process. This was approached with a horizontal incision $3 \mathrm{~cm}$ below the mandible, and an elongated styloid process was identified deep to the digastric muscle. Approximately $3.5 \mathrm{~cm}$ of styloid process was excised. He was reviewed 6 weeks postoperatively and symptoms had completely resolved and was patient discharged.

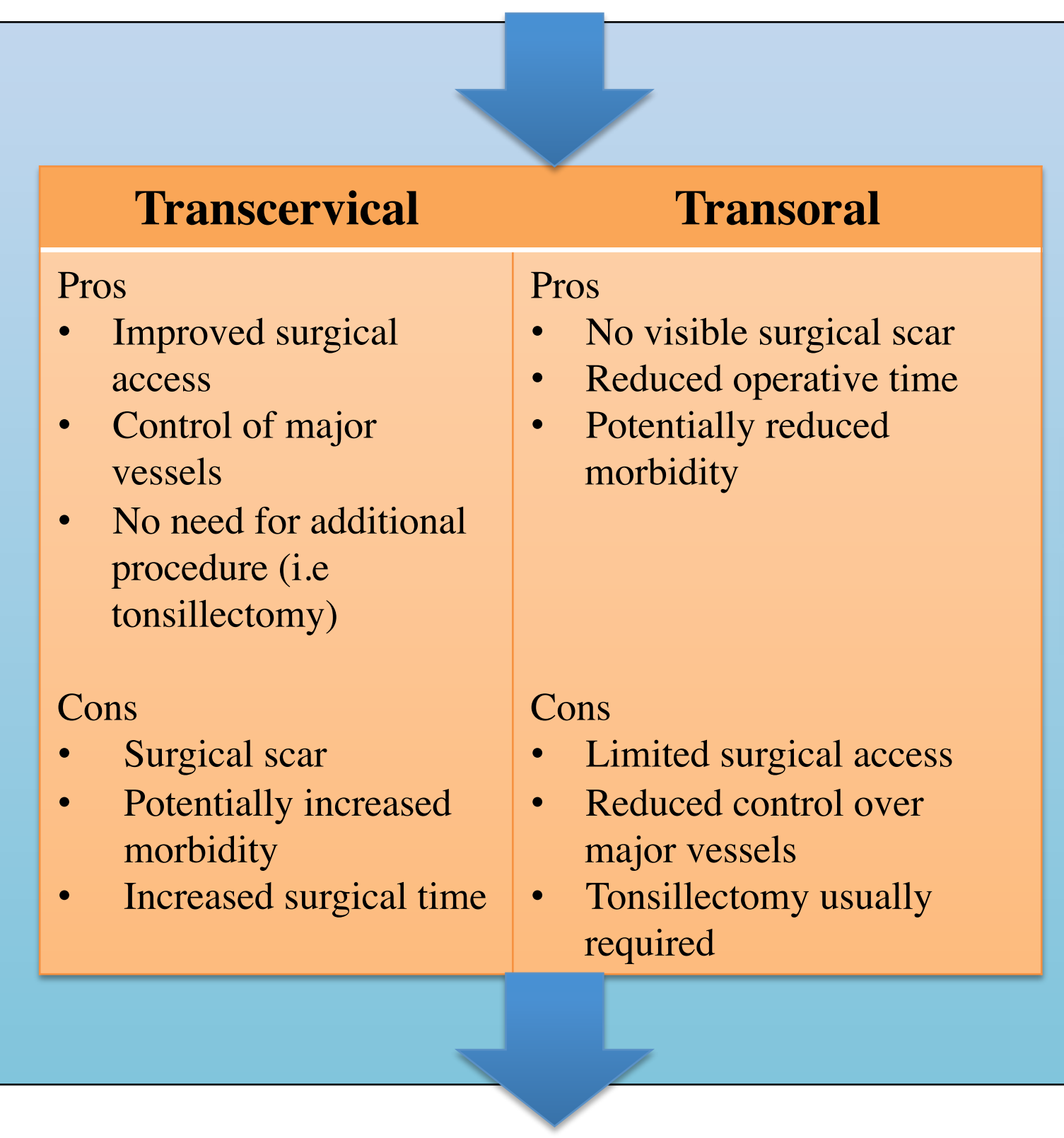

\section{Conclusion}

While Eagle syndrome is a rare condition it can cause debilitating symptoms for affected patients. Both transcervical and transoral approaches to treatment are well established, and these two cases showed favourable outcomes with both techniques.

*Royal Blackburn Teaching Hospital Department of Otolaryngology Haslingden Road, Blackburn, BB2 3HH United Kingdom

Email: $\underline{\operatorname{mjunaid} @ \text {,nhs.net }}$

\section{Case 2- Transoral approach}

\section{Case presentation}

48 year old lady referred by her GP with 6 month history of chronic cough, burning sensation in throat and globus sensation. A CT scan was arranged for suspected Eagle syndrome, and this confirmed bilateral elongation and calcification of the styloid process (Figure 1).

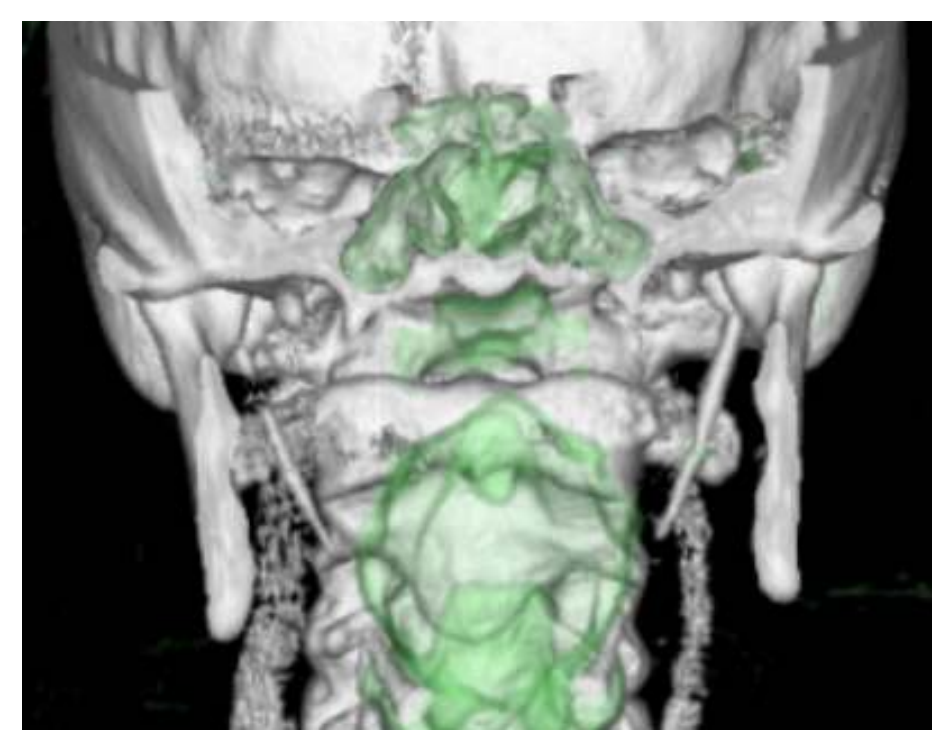

Figure 1. CT reconstruction demonstrating bilateral styloid process elongation

\section{Procedure}

An intraoral approach was undertake. Initially a left tonsillectomy was performed followed by blunt dissection onto the left styloid process. Attached ligaments were removed with monopolar diathermy and approximately $1.3 \mathrm{~cm}$ of styloid process was excised (Figures 2 and 3). At her post operative clinic review she reported significant improvement in her symptoms.

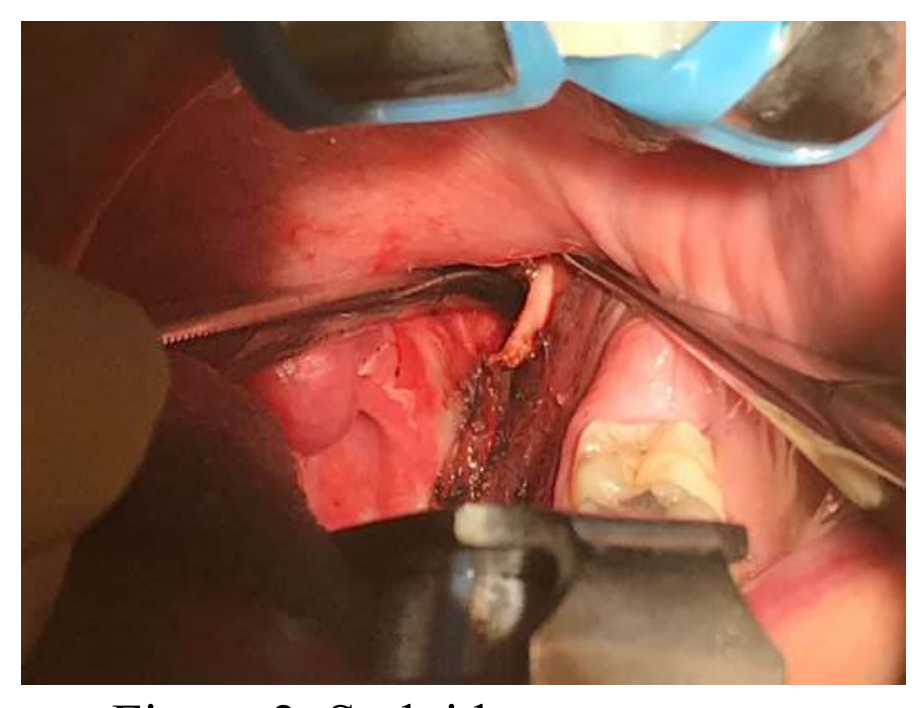

Figure 2. Styloid process seen following left tonsillectomy

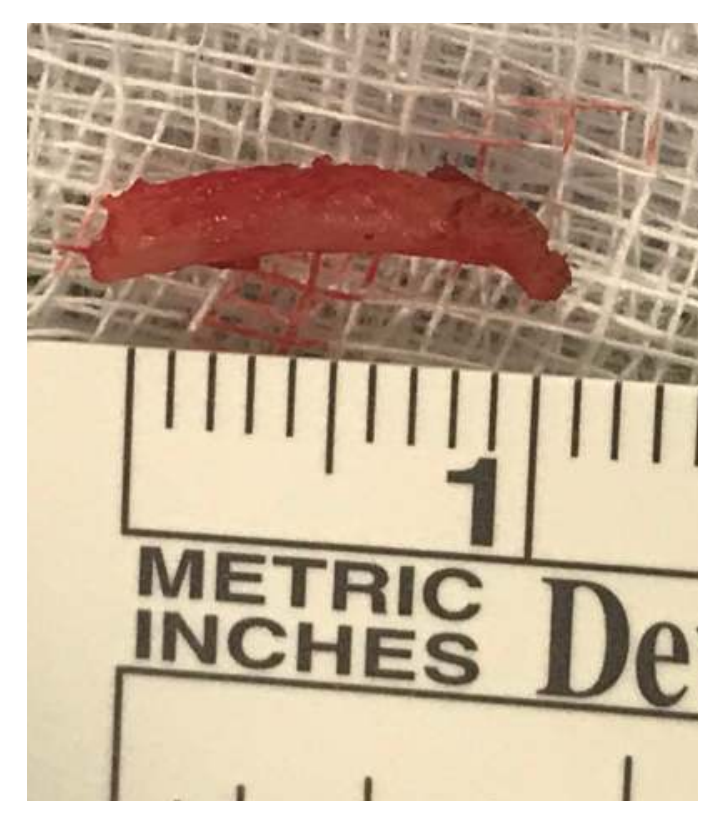

Figure 3. Surgical specimen of excised styloid process 